\title{
Transdermal Drug Delivery Treatment for Overactive Bladder
}

\author{
Roger R. Dmochowski, Jonathan S. Starkman, G. Willy Davila \\ Vanderbilt University Medical Center (RRD, JSS) and Section of Urogynecology and Reconstructive \\ Pelvic Surgery (GWD), Cleveland Clinic Florida, Weston, Florida, USA
}

\begin{abstract}
Overactive bladder is commonly treated with oral anticholinergic drugs such as oxybutynin chloride. Although oral anticholinergic agents have been effective in controlling urinary urgency and incontinence, adverse events, particularly dry mouth, often cause patients to discontinue oral therapy and to endure incontinence. Oxybutynin can be delivered transcutaneously, maintaining the efficacy of oral oxybutynin while significantly minimizing side effects (e.g., dry mouth) that may complicate therapy. By avoiding hepatic and gastrointestinal metabolism of oxybutynin, less N-desethyloxybutynin (N-DEO) is produced and this compound is deemed to be responsible for anticholinergic side effects such as dry mouth. This novel oxybutynin formulation offers patients with $\mathrm{OAB}$ and urge urinary incontinence a well-tolerated option for managing the symptoms of overactive bladder.
\end{abstract}

Key words: overactive bladder; oxybutynin; administration, cutaneous; urinary incontinence Int Braz J Urol. 2006; 32: 513-20

\section{INTRODUCTION}

Overactive bladder $(\mathrm{OAB})$ syndrome is a common symptom complex that affects as many as 33 million Americans and more from across the world (1). Management of OAB has become standardized to some degree as pharmacotherapy coupled with behavioral techniques is usually considered first line treatment (2-4). Despite the existence of effective therapy for $\mathrm{OAB}$, at any given time only a fraction of patients is receiving therapy. Reasons for this disparity are likely multifactorial, and include issues related to cost of therapy, patient and physician attitudes, a heterogeneous patient population with respect to symptom severity and response to therapy, and side effects related to drug therapy. When assessing the various pharmacotherapies for $\mathrm{OAB}$, anti-cholinergic medications are currently considered standard of care. Efficacy of drug therapy is achieved via muscarinic receptor blockade at the end organ level. Five muscarinic receptor subtypes (M1-M5) have been identified, the distribution of which varies depending on the particular organ system. In the bladder, the predominant receptors are the M2 and M3 subtypes. Although the M2 subtype is the most abundant receptor in the bladder, it appears that the $\mathrm{M} 3$ receptor subtype is most directly responsible for the symptoms of OAB as it mediates detrusor contractility (5-7).

Oral oxybutynin has been the most commonly prescribed treatment for OAB for nearly 30 years. In recent years, a number of alternatives have been introduced, including tolterodine, tropsium, solifenacin, and darifenacin. Extended release formulations of oxybutynin and tolterodine result in 
controlled release of drug and steady plasma concentrations, improving tolerability compared to immediate-release (IR) dosing (8-10). Despite this, the major limitation of pharmacotherapy for $\mathrm{OAB}$ remains the significant incidence of anti-cholinergic side effects secondary to antagonism of muscarinic receptors at the level of the salivary gland, gastrointestinal tract, and central nervous system $(11,12)$. These adverse effects negatively impact patient compliance and overall quality of life, often leading to patient initiated discontinuation of drug therapy.

\section{NOVEL DELIVERY}

Intrarectal, intravesical, and intravaginal oxybutynin have been administered in clinical trials in an attempt to avoid first-pass hepatic metabolism of the drug (13-17). In one study, intrarectal oxybutynin was shown to be efficacious and more tolerable than oral oxybutynin (13), while another study demonstrated that a significant number of patients still experience adverse events (dry mouth and constipation) (14). Intravesical oxybutynin administered via catheterization has shown acceptable efficacy and tolerability in several studies. One study showed that aqueous oxybutynin 2-3 times daily eliminated or significantly reduced urge incontinence episodes in 55\% of the patients (16). Another small study demonstrated improvement in cystometric parameters and patient satisfaction with modified intravesical oxybutynin (intravesical oxybutynin with hydroxypropylcellulose, $5 \mathrm{mg} / 10 \mathrm{~mL}$ ) (18). While the clinical studies showed that there were minimal anticholinergic side effects affecting patient tolerability, inconvenience with self catheterization and treatment induced symptoms of cystitis may limit widespread acceptance of intravesical oxybutynin therapy (19). Furthermore, there may be issues related to contaminants involved in the preparation of aqueous oxybutynin for intravesical delivery. Despite observed clinical efficacy, there are no commercial preparations of oxybutynin rectal suppositories available and intravesical oxybutynin would only appear reasonable in patients performing intermittent self catheterization, making it an inconvenient option for most patients with OAB. Randomized clinical trials evaluating safety and efficacy of an oxybutynin vaginal ring delivery system are currently ongoing.

There have been significant improvements in transdermal drug delivery systems, moving away from older liquid reservoir systems to current matrix type patches and aqueous gels. Advantages of transdermal systems in general include the avoidance of the gastrointestinal tract and first-pass hepatic metabolism, in addition to allowing drugs with relatively poor bioavailability to attain therapeutic serum levels at low dosages. Currently, a number of transdermal medications are available commercially including testosterone, estrogen, fentanyl, scopolamine, clonidine, nicotine, and oxybutynin (20).

\section{OXYBUTYNIN MECHANISM OF ACTION}

Oxybutynin $(\mathrm{OXY})$ is a tertiary amine that exists commercially as a racemic mixture of $\mathrm{R}$ - and $S$ - enantiomers. The mechanism of action of oxybutynin is 2 -fold, consisting of 1) its antimuscarinic properties and 2) its spasmolytic action on detrusor smooth muscle cells $(21,22)$. Oxybutynin exhibits stereoselectivity, as R-OXY has greater anticholinergic activity compared to S-OXY. The spasmolytic effects on smooth muscle appear to be equal for the R- and S- isomers $(23,24)$.

Transdermal oxybutynin (OXY-TDS) is a matrix-type patch composed of 3 layers consisting of a backing film (polyester/ethylene-vinyl acetate-PET/ EVA), adhesive matrix layer (containing oxybutynin free base), and an overlapping release liner strip (Figure-1). The backing film (Layer 1) has an occlusive function, which serves to protect the adhesive/drug layer, while the release liner contains 2 overlapped silicone coated polyester strips. This system is applied to the skin after peeling off the plastic tab of the release liner. OXY-TDS contains 36 mg of oxybutynin and triacetin (permeation enhancer) dissolved in an acrylic block copolymer adhesive with a surface areas of $39 \mathrm{~cm}^{2}(25)$. The average daily dose of oxybutynin absorbed from the $39 \mathrm{~cm}^{2}$ Oxytrol ${ }^{\mathrm{TM}}$ 


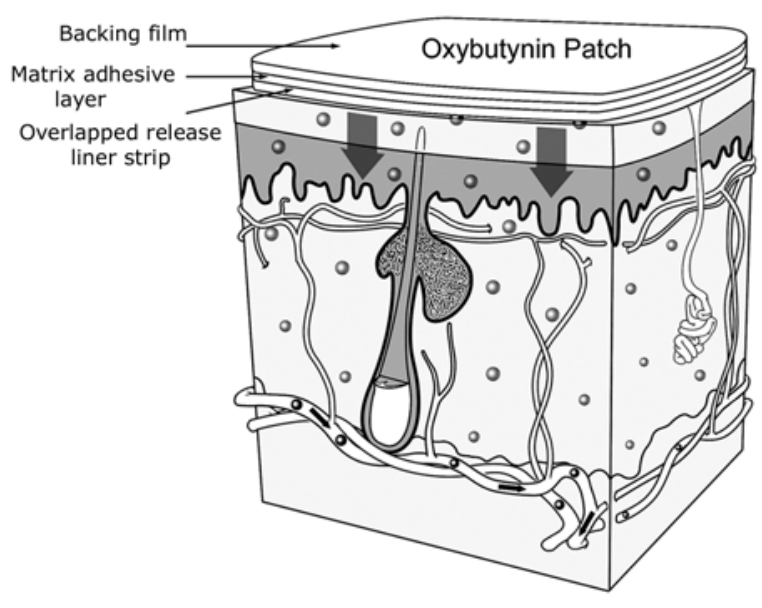

Figure 1 - Transdermal oxybutynin system.

system is $3.9 \mathrm{mg} /$ day $\left(0.1 \mathrm{mg} / \mathrm{cm}^{2}\right)$. Absorption of drug requires penetration of the lipid rich stratum corneum of the skin and the more aqueous epidermis and dermis. Thus, oxybutynin must possess both lipophilic and hydrophilic properties. Once contact is established between the skin and OXY-TDS, diffusion of oxybutynin and the permeation enhancer occurs across the stratum corneum, controlled by the interaction of oxybutynin and enhancer with lipids in the skin (25). Oxybutynin is then absorbed by the capillary microcirculation in the dermis of the skin and delivered into the systemic circulation, thus bypassing first-pass metabolism by the liver (Figure1). Avoidance of hepatic metabolism reduces conversion of oxybutynin to its chief metabolite, Ndesethyloxybutynin (N-DEO), which is thought to mediate much of the adverse anticholinergic side effects attributed to OXY. The OXY-TDS patch can also be incised/cut prior to application to improve tolerability without compromising efficacy. Potential benefits of transdermal oxybutynin include the avoidance of pre-systemic metabolism in the gut and liver $(25,26)$ (Table-1).

\section{OXYBUTYNIN PHARMACOKINETICS}

Following oral administration, oxybutynin undergoes extensive first-pass metabolism in the liver, with an additional portion metabolized within the lumen of the GI tract. As a result, the bioavailability after an oral dose of oxybutynin is only $6 \%$. Hepatic metabolism (Cytochrome P450, CYP3A4) results in the conversion of oxybutynin (OXY) to $\mathrm{N}$ desethyloxybutynin (N-DEO) and levels of N-DEO reach plasma concentrations that are between 4 and 10 times the concentration of native oxybutynin $(27,28)$. Many of the anticholinergic side effects, particularly dry mouth, of oral oxybutynin are thought to be secondary to N-DEO, which has been shown in

Table 1 - Transdermal drug delivery systems.

\section{Advantages}

- Improves compliance. No pills to remember.

- Slow and steady release of drug results in more consistent plasma concentrations.

- Avoids first-pass hepatic and gastrointestinal metabolism.

\section{Disadvantages}

- Patients must change patch after defined dosage period.

- Requires careful disposal as patch may still contain active medication

- Limited number of drugs may be used by transdermal system.

- Local dermatologic reactions at the application site

- Difficulty with patch adhesion to skin occurs in limited number of cases

- Variable absorption secondary to individual skin characteristics and local dermal metabolism. 
studies to bind to muscarinic receptors in the parotid gland with higher affinity than OXY (29). As there are only small amounts of CYP3A4 found in the skin, transdermal delivery of oxybutynin avoids presystemic metabolism and results in lower plasma levels of N-DEO. Thus, there is the potential for less anticholinergic adverse events.

A study by Zobrist et al. (25), evaluated the in vitro and in vivo pharmacokinetics and metabolism of transdermal oxybutynin. After initial transdermal application there is a 2-hour window until measurable plasma levels of drug are detectable, followed by a gradual increase in mean OXY and N-DEO plasma levels over a 24-36 hour time period, reaching average maximum concentrations of 3 to $4 \mathrm{ng} / \mathrm{mL}$. Levels of drug then plateau and remain relatively stable for another 24 hours before declining throughout the remainder of the 96-hour dosing interval. Following the removal of the transdermal system there is a consistent and transient increase in plasma drug concentrations over 30 minutes, and a rapid decline in plasma concentrations thereafter. Another randomized crossover study by Zobrist et al. (26) evaluated the pharmacokinetics of the R- and Senantiomers of oxybutynin following oral and transdermal administration. In vitro skin flux experiments reveal that there is equal absorption of $\mathrm{R}$ - and S- oxybutynin through the human epidermis with a mean ratio of R-OXY/S-OXY of $1.00 \pm 0.02$. In contrast to the in vitro data, stereoselective metabolism was observed in vivo for both transdermal and oral oxybutynin. Because the $\mathrm{R}$ isomer possesses greater receptor affinity and N-DEO is thought to play an important role in anticholinergic side effects, the distinct differences in metabolite concentrations following both transdermal and oral administration support the possibility of improved tolerability and comparable efficacy with the transdermal delivery system. In a crossover study by Appell et al. (30), pharmacokinetic parameters and saliva output were assessed following both transdermal and extendedrelease oxybutynin (OXY ER) administration. Steady state plasma concentrations were attained following the first transdermal application and second ER oral tablet. Stereoselective metabolism was observed for both the R- and S- isomers of OXY and N-DEO that paralleled data previously reported (26).

Saliva output has been shown in previous studies to be a valid surrogate marker of dry mouth $(31,32)$. Saliva output was greater in patients receiving transdermal therapy when compared to extended release oral therapy. An inverse relationship was observed between N-DEO and saliva output, with lower levels of N-DEO correlating with greater total saliva weight, corresponding to the low incidence of dry mouth observed with administration of transdermal oxybutynin. A comparative review of the pharmacokinetic parameters of oxybutynin IR, oxybutynin ER, and oxybutynin TDS is provided in Table-2.

Table 2 - Comparative steady state pharmacokinetic parameters of oxybutynin immediate-release (IR), oxybutynin extendedrelease (ER), and oxybutynin transdermal (TDS).

\begin{tabular}{llccccc}
\hline Agent & Dosage & $\begin{array}{c}\text { Mean Cmax } \\
(\mathbf{n g} / \mathbf{m L})\end{array}$ & $\begin{array}{c}\text { Mean AUC } \\
(\mathbf{n g} \cdot \mathbf{h} / \mathbf{m L})\end{array}$ & Mean T1/2 (h) & N-DEO / OXY & Ref. \\
\hline Oxybutynin TDS & $\begin{array}{l}3.9 \mathrm{mg} \mathrm{qd} \\
\Delta 3-4 \mathrm{~d}\end{array}$ & $6.6(2.4)$ & $408(108)$ & $7-8$ & $1.3: 1(0.3)$ & 25,38 \\
Oxybutynin IR & $5 \mathrm{mg}$ tid & $12.4(4.1)$ & $81(43)$ & $9.0(2.4)$ & $5.5: 1$ & 25,39 \\
Oxybutynin ER & $15 \mathrm{mg} \mathrm{qd}$ & $6.7(2.1)$ & $109(43)$ & $13.8(2.9)$ & $4.1: 1(0.9)$ & 30,39 \\
\hline
\end{tabular}

Standard deviation of the mean is in parenthesis; Cmax = mean peak serum concentration; $A U C=$ area under the curve; $N$-DEO = $N$-desethyloxybutynin; $O X Y=$ oxybutynin. 


\section{TRANSDERMAL OXYBUTYNIN CLINICAL RESULTS}

The efficacy of OXY-TDS has been evaluated in several clinical trials. A short-term, multicenter, double blind, dose-titration study compared OXYTDS to immediate release oxybutynin in patients with urinary urge incontinence (33). Seventy-six patients with detrusor overactivity who were currently responding to oxybutynin IR were randomized to transdermal $(\mathrm{N}=38)$ and oral therapy $(\mathrm{N}=38)$ following a 2-week washout phase. Outcome measures included daily incontinence episodes recorded on 3 day bladder diaries, side effects recorded utilizing an anticholinergic symptom questionnaire, and visual analog scale measuring urinary control. Dose titration was initiated at levels based on previous oxybutynin IR dose and adjusted according to side effect profile, with the goal to achieve the maximal tolerable dose. Average daily incontinence episodes decreased in both treatment groups compared to washout by 5 , $(\mathrm{p}<0.0001)$ with no significant difference observed based on type of therapy (OXY-TDS from 7.2 to 2.4 and oxybutynin IR from 7.2 to $2.6 ; p=0.39$ ). Side effects were measured utilizing a non-validated anticholinergic symptom questionnaire and were rated as mild, tolerable, and intolerable. Dry mouth was rated as absent, mild, tolerable, and intolerable in $62 \%, 27 \%$, $11 \%$ and $0 \%$ of patients treated with OXY-TDS. The corresponding values for patients treated with oxybutynin IR were $6 \%, 26 \%, 59 \%$ and $9 \%$. Constipation was observed in $21 \%$ of patients in the transdermal group and $50 \%$ of patients in the oral group. In general, other side effects were described by fewer patients with less variance between the 2 treatment cohorts and included somnolence, dizziness, blurred vision, and impaired urination. Adverse effects unique to transdermal drug delivery systems included erythema at the patch application site with both active and placebo patches. Mild, moderate, and severe erythema was observed in $18 \%, 4 \%$, and $1 \%$ of placebo patches and in $30 \%, 7 \%$, and $1 \%$ of active therapy patches.

In another multi-center, double blind study, 520 patients with urge and mixed urinary incontinence were randomized to receive 3 doses of OXY-TDS (1.3 $\mathrm{mg} / \mathrm{d}, 2.6 \mathrm{mg} / \mathrm{d}$, or $3.9 \mathrm{mg} / \mathrm{d}$ ) or placebo, followed by a 12-week open-label, dose titration period to further evaluate efficacy and safety. Doses of $3.9 \mathrm{mg} / \mathrm{d}$ OXYTDS led to a significant improvement in number of incontinence episodes/week (median change -19 vs. $-14.5 ; \mathrm{p}=0.0165$ ), mean daily frequency (mean change -2.3 vs. $-1.7 ; p=0.0457$ ), average voided volume (median increase of $24 \mathrm{cc}$ vs. $6 \mathrm{cc} ; \mathrm{p}=0.0063$ ), and quality of life as measured by the total score on the Incontinence Impact Questionnaire (39\% improvement vs. $28 \% ; \mathrm{p}=0.0327$ ) compared to placebo treatment. Doses of $2.6 \mathrm{mg} / \mathrm{d}$ significantly improved average voided volume $(19 \mathrm{~mL} ; \mathrm{p}=.0157)$, however there were no other significant differences between the $1.3 \mathrm{mg}$ and $2.6 \mathrm{mg}$ groups compared to placebo treatment.

Safety was evaluated in all patients who participated in the double-blind study $(\mathrm{N}=520)$, as well as the 12-week, open-label, dose titration period $(\mathrm{N}=411)$. Application site skin reactions were the most commonly observed adverse events related to treatment, with the vast majority being mild to moderate in intensity. Erythema was observed in $3.1 \%, 4.5 \%$, and $5.6 \%$ with $1.3,2.6$, and $3.9 \mathrm{mg} / \mathrm{d}$ transdermal oxybutynin compared to $2.3 \%$ with placebo. Pruritis was observed in $10.8 \%, 13.5 \%$, and $16.8 \%$ of patients receiving active treatment compared to $6.1 \%$ with placebo. Withdrawal from the study was most commonly related to skin reactions and was seen in $10.2 \%$ of patients in the double blind period and $7.3 \%$ of patients during the dose titration period. Dry mouth was the most common anticholinergic side effect reported in the study and incidence did not differ between OXY-TDS and placebo (7\% vs. $8.3 \%$; $\mathrm{p}=$ ns). Other anticholinergic side-effects occurred infrequently and did not differ from placebo. The comparative efficacy and safety of transdermal oxybutynin, oral tolterodine and placebo were assessed in another double-blind, multi-center study (34). Three-hundred and sixty-one responders to previous pharmacotherapy were randomized to transdermal oxybutynin $(3.9 \mathrm{mg} / \mathrm{d}$, twice weekly), extended release tolterodine (4 mg daily), or placebo following a 2-week washout period. Patients were evaluated with regard to urinary symptoms based on 
voiding diaries, incontinence-specific quality of life, and tolerability/safety. Patients treated with OXYTDS achieved statistically significant reductions in daily incontinence episodes ( -3 vs. $-2 ; \mathrm{p}=0.0137)$, increased average voided volume ( $24 \mathrm{cc}$ vs. $5.5 \mathrm{cc} ; \mathrm{p}$ $=0.001$ ), and improved quality of life (Incontinence Impact Questionnaire, $\mathrm{p}=0.0018$ and Urogenital Distress Inventory, $\mathrm{p}=0.0156$ ). Tolterodine ER also improved measured outcomes in a statistically significant fashion compared to placebo treatment. Active treatment resulted in a $75 \%$ reduction in daily incontinence episodes for OXY-TDS and tolterodine ER compared to a $50 \%$ reduction with placebo (both $\mathrm{p}<0.05$ vs. placebo). One-hundred and twenty patients were continent upon completion of the study, including 47 (39\%), 47 (38\%), and 26 (22\%) patients receiving OXY-TDS, tolterodine ER, and placebo (both $\mathrm{p}=0.014$ vs. placebo). There were no significant differences in any evaluated outcome parameters between the 2 active treatment arms of the study.

Systemic adverse events occurred more frequently with tolterodine ER (23.6\%) compared to OXY-TDS (19\%) and placebo (12\%). The vast majority of these were classified as mild and moderate. Dry mouth occurred in $4.1 \%$ of patients receiving OXY-TDS and $7.3 \%$ of patients receiving tolterodine ER compared to $1.7 \%$ with placebo (TDS, $\mathrm{p}=0.2678$; tolterodine $\mathrm{ER}, \mathrm{p}=0.0379$ ). Constipation occurred in $3.3 \%$ and $5.7 \%$ of OXY-TDS and tolterodine ER treated patients, respectively. Application site skin reactions were the most common adverse events observed with transdermal oxybutynin therapy, and included pruritis (14\% with transdermal vs. $4.3 \%$ with placebo) and erythema (8.3\% with transdermal vs. 1.7 with placebo). Twenty-six of the 32 dermatologic adverse effects were rated by patients as mild or moderate. Twelve patients discontinued treatment in the OXY-TDS group as a result of skin site reactions, while 2 patients withdrew due to tolterodine ER related side effects.

Another study pooled data analysis from the 2 double-blind, phase 3 trials to better determine the safety and efficacy of OXY-TDS (35). The 241 patients that received $3.9 \mathrm{mg} / \mathrm{d}$ transdermal oxybutynin and 244 patients that received placebo treatment were included in the data analysis. Results from the study showed statistically significant improvements in daily incontinence episodes, daily urinary frequency, urinary voided volume, and quality of life scores. Adverse events determined to be related to therapy occurred in $100(41.3 \%)$ and $61(24.9 \%)$ patients receiving active treatment compared to placebo. The benefit of placebo therapy in overactive bladder clinical trials has been well established. The observed improvements in patients treated with placebo in various clinical trials have been attributed to behavioral therapies (36). Patients in the current study were instructed to maintain normal fluid intake and continue with all nonpharmacologic modalities (e.g., timed voiding and pelvic floor muscle exercises). Another unique aspect of the study was the difference in clinical inclusion criteria used for study enrollment. Eighty percent of study 1 (37) participants reported no history of previous treatment with anticholinergic medications while $100 \%$ of study 2 (34) participants were known responders to anticholinergic therapy. Despite these different populations, efficacy of OXY-TDS was similar with respect to measured outcome parameters.

\section{TRANSDERMAL OXYBUTYNIN SUMMARY}

Transdermal oxybutynin has shown comparable efficacy and improved tolerability when compared to conventional pharmacotherapy. Systemic anticholinergic adverse effects are comparable to placebo, most likely due to avoidance of first pass hepatic metabolism and conversion of oxybutynin to $\mathrm{N}$-desethyloxybutynin. OXY-TDS has predictable pharmacokinetic absorption and elimination parameters as shown in both in vitro and in vivo studies. Consistent plasma concentrations of oxybutynin avoid labile peak and trough concentrations seen with IR formulations, paralleling ER drug delivery. This novel drug delivery system has unique dermatologic skin application site reactions, including erythema and pruritus. Skin reactions are usually mild in severity and can be minimized by varying the site of patch application. 
Most eczematous dermatologic reactions can be appropriately treated with a moderately potent topical corticosteroid cream. In conclusion, transdermal oxybutynin is an excellent treatment option for patients who find the side effects of oral antimuscarinics intolerable, as well as those patients who do not wish to administer their medication on a daily basis.

\section{CONFLICT OF INTEREST}

Doctor G. Willy Davila is consultant to Watson, the manufacturer of the transdermal oxybutynin patch.

\section{REFERENCES}

1. Wein AJ, Rovner ES: Definition and epidemiology of overactive bladder. Urology. 2002; 60(5 Suppl 1): 7 12; discussion 12.

2. Burgio KL, Goode PS, Locher JL, Richter HE, Roth DL, Wright KC, et al.: Predictors of outcome in the behavioral treatment of urinary incontinence in women. Obstet Gynecol. 2003; 102: 940-7.

3. Mattiasson A, Blaakaer J, Hoye K, Wein AJ; Tolterodine Scandinavian Study Group: Simplified bladder training augments the effectiveness of tolterodine in patients with an overactive bladder. BJU Int. 2003; 91: 54-60.

4. Dmochowski RR: The puzzle of overactive bladder: controversies, inconsistencies, and insights. Int Urogynecol J Pelvic Floor Dysfunct. 2005; 14: 1-9.

5. Chess-Williams R, Chapple CR, Yamanishi T, Yasuda K, Sellers DJ: The minor population of M3-receptors mediate contraction of human detrusor muscle in vitro. J Auton Pharmacol. 2001; 21: 243-8.

6. Andersson KE, Yoshida M: Antimuscarinics and the overactive detrusor-which is the main mechanism of action? Eur Urol. 2003; 43: 1-5.

7. Fetscher C, Fleichman M, Schmidt M, Krege S, Michel MC: M(3) muscarinic receptors mediate contraction of human urinary bladder. Br J Pharmacol. 2002; 136: 641-3.

8. Appell RA, Sand P, Dmochowski R, Anderson R, Zinner N, Lama D, et al.: Prospective randomized controlled trial of extended-release oxybutynin chloride and tolterodine tartrate in the treatment of overactive bladder: results of the OBJECT Study. Mayo Clin Proc. 2001; 76: 358-63.

9. Diokno AC, Appell RA, Sand PK, Dmochowski RR, Gburek BM, Klimberg IW, et al.: Prospective, randomized, double-blind study of the efficacy and tolerability of the extended-release formulations of oxybutynin and tolterodine for overactive bladder: results of the OPERA trial. Mayo Clin Proc. 2003; 78: 687-95.

10. Sussman D, Garely A: Treatment of overactive bladder with once-daily extended-release tolterodine or oxybutynin: the antimuscarinic clinical effectiveness trial (ACET). Curr Med Res Opin. 2002; 18: 177-84.

11. Lawrence M, Guay DR, Benson SR, Anderson MJ: Immediate-release oxybutynin versus tolterodine in detrusor overactivity: a population analysis. Pharmacotherapy. 2000; 20: 470-5.

12. Scarpero HM, Dmochowski RR: Muscarinic receptors: what we know. Curr Urol Rep. 2003; 4: 421-8.

13. Radziszewski P, Borkowski A: Therapeutic effects of intrarectal administration of oxybutynin. Wiad Lek. 2002; 55: 691-8.

14. Winkler HA, Sand PK: Treatment of detrusor instability with oxybutynin rectal suppositories. Int Urogynecol J Pelvic Floor Dysfunct. 1998; 9: 1002.

15. Saito M, Tabuchi F, Otsubo K, Miyagawa I: Treatment of overactive bladder with modified intravesical oxybutynin chloride. Neurourol Urodyn. 2000; 19: 683-8.

16. Weese DL, Roskamp DA, Leach GE, Zimmern PE: Intravesical oxybutynin chloride: experience with 42 patients. Urology. 1993; 41: 527-30.

17. Chou EC, Whitbeck C, Borow A, Burden O, Levin RM: Inhibition of hyperreflexia by vaginally administered oxybutynin: a novel rabbit model. J Urol. 2004; 171: 958-62.

18. Saito M, Watanabe T, Tabuchi F, Otsubo K, Satoh K, Miyagawa I: Urodynamic effects and safety of modified intravesical oxybutynin chloride in patients with neurogenic detrusor overactivity: 3 years experience. Int J Urol. 2004; 11: 592-6.

19. Guerrero K, Emery S, Owen L, Rowlands M: Intravesical oxybutynin: practicalities of clinical use. J Obstet Gynaecol. 2006; 26: 141-3.

20. Richelson E, Elliott DS: Advances in medical management of overactive bladder. Mayo Clin Proc. 2003; 78: 681-3.

21. Lish PM, Labudde JA, Peters EL, Robbins SI: Oxybutynin-a musculotropic antispasmodic drug 
with moderate anticholinergic action. Arch Int Pharmacodyn Ther. 1965; 156: 467-88.

22. Noronha-Blob L, Lowe VC, Peterson JS, Hanson RC: The anticholinergic activity of agents indicated for urinary incontinence is an important property for effective control of bladder dysfunction. J Pharmacol Exp Ther. 1989; 251: 586-93.

23. Kachur JF, Peterson JS, Carter JP, Rzeszotarski WJ, Hanson RC, Noronha-Blob L: R and S enantiomers of oxybutynin: pharmacological effects in guinea pig bladder and intestine. J Pharmacol Exp Ther. 1988; 247: 867-72.

24. Noronha-Blob L, Kachur JF: Enantiomers of oxybutynin: in vitro pharmacological characterization at M1, M2 and M3 muscarinic receptors and in vivo effects on urinary bladder contraction, mydriasis and salivary secretion in guinea pigs. J Pharmacol Exp Ther. 1991; 256: 562-7.

25. Zobrist RH, Quan D, Thomas HM, Stanworth S, Sanders SW: Pharmacokinetics and metabolism of transdermal oxybutynin: in vitro and in vivo performance of a novel delivery system. Pharm Res. 2003; 20: 103-9.

26. Zobrist RH, Schmid B, Feick A, Quan D, Sanders SW: Pharmacokinetics of the R- and S-enantiomers of oxybutynin and $\mathrm{N}$-desethyloxybutynin following oral and transdermal administration of the racemate in healthy volunteers. Pharm Res. 2001; 18: 1029-34.

27. Gupta SK, Shah JC, Hwang SS: Pharmacokinetic and pharmacodynamic characterization of OROS and immediate-release amitriptyline. Br J Clin Pharmacol. 1999; 48: 71-8.

28. Massad CA, Kogan BA, Trigo-Rocha FE: The pharmacokinetics of intravesical and oral oxybutynin chloride. J Urol. 1992; 148: 595-7.

29. Waldeck K, Larsson B, Andersson KE: Comparison of oxybutynin and its active metabolite, N-desethyloxybutynin, in the human detrusor and parotid gland. J Urol. 1997; 157: 1093-7.

30. Appell RA, Chancellor MB, Zobrist RH, Thomas H, Sanders SW: Pharmacokinetics, metabolism, and saliva output during transdermal and extended-release oral oxybutynin administration in healthy subjects. Mayo Clin Proc. 2003; 78: 696-702.

31. Ross CE, Toon S, Rowland M, Murray GH, Meya U: A study to assess the anticholinergic activity of rolipram in healthy elderly volunteers. Pharmacopsychiatry. 1988; 21: 222-5.

32. Sathyan G, Chancellor MB, Gupta SK: Effect of OROS controlled-release delivery on the pharmacokinetics and pharmacodynamics of oxybutynin chloride. $\mathrm{Br} \mathrm{J}$ Clin Pharmacol. 2001; 52: 409-17.

33. Davila GW, Daugherty CA, Sanders SW; Transdermal Oxybutynin Study Group: A short-term, multicenter, randomized double-blind dose titration study of the efficacy and anticholinergic side effects of transdermal compared to immediate release oral oxybutynin treatment of patients with urge urinary incontinence. $\mathrm{J}$ Urol. 2001; 166: 140-5.

34. Dmochowski RR, Sand PK, Zinner NR, Gittelman MC, Davila GW, Sanders SW, et al.: Comparative efficacy and safety of transdermal oxybutynin and oral tolterodine versus placebo in previously treated patients with urge and mixed urinary incontinence. Urology. 2003; 62: 237-42.

35. Dmochowski RR, Nitti V, Staskin D, Luber K, Appell R, Davila GW: Transdermal oxybutynin in the treatment of adults with overactive bladder: combined results of two randomized clinical trials. World J Urol. 2005; 23: 263-70.

36. Burgio KL, Locher JL, Goode PS, Hardin JM, McDowell BJ, Dombrowski M, et al.: Behavioral vs drug treatment for urge urinary incontinence in older women: a randomized controlled trial. JAMA. 1998; 280: 1995-2000.

37. Dmochowski RR, Davila GW, Zinner NR, Gittelman MC, Saltzstein DR, Lyttle S, et al.: Efficacy and safety of transdermal oxybutynin in patients with urge and mixed urinary incontinence. J Urol. 2002; 168: 580-6.

38. Oxytrol (package insert). Corona (CA): Watson Pharma Inc, 2003.

39. Gupta SK, Sathyan G: Pharmacokinetics of an oral once-a-day controlled-release oxybutynin formulation compared with immediate-release oxybutynin. J Clin Pharmacol. 1999; 39: 289-96.

$\overline{\text { Accepted: }}$

April 10, 2006 